\title{
2,2'-Diphenyl-1-picrylhydrazyl and 2,2'-azinobis-(3-ethyl- benzothiazoline-6-sulfonic acid) scavenging assay of Extract and Fractions of Rambutan (Nephelium lappaceum L.) Seed
}

\author{
M. J. Budikafa ${ }^{1}$, Rumiyati ${ }^{1}$, S. Riyanto ${ }^{1}$ and A. Rohman ${ }^{1,2}$ \\ ${ }^{1}$ Department of Pharmaceutical Chemistry, Faculty of Pharmacy, Universitas Gadjah Mada \\ Yogyakarta, 55281, Indonesia \\ ${ }^{2}$ Reseach Center of Halal Products, Universitas Gadjah Mada, Yogyakarta, 55281, Indonesia
}

(Received: October 11, 2018; Accepted: May 23, 2019; Published (Web): October 5, 2019)

\begin{abstract}
This research was intended to evaluate the antiradical activity of extracts and fractions of rambutan seed using 2,2'diphenyl-1-picrylhydrazyl (DPPH) and 2,2'-azinobis-(3-ethylbenzothiazoline-6-sulfonic acid) ( $\mathrm{ABTS}^{*+}$ ). The powder of rambutan seed was subjected to maceration with methanol. The methanolic extract obtained was then fractionated using petroleum ether (PE), dichloromethane (DCM) and ethyl acetate (EA) to obtain PE, DCM and EA fractions, respectively. The methanol extract and fractions were then assayed for antiradical activities and phenolics and flavonoid contents.The results showed that EA fraction has lowest $\mathrm{IC}_{50}$ values among extract and fractions evaluated, i.e. $244.6 \pm 2.1 \mu \mathrm{g} / \mathrm{ml}$ using DPPH radical. Using ABTS radical, EA fraction $(0.1 \%)$ also revealed the highest antiradical activity of $643.4 \pm 34.9 \mu \mathrm{M}$ trolox equivalent. However, these antiradical activities were lower than those in positive controls used (vitamin $\mathrm{C}$ and vitamin $\mathrm{E}$ ). The antiradical activities of extract and fractions correlated with total phenolics and flavonoid contents. The seed of rambutan fruit could be exploited as natural antioxidants to be used in food supplements.
\end{abstract}

Key words: Rambutan seed, antiradical activities, DPPH, ABTS, phenolics contents.

\section{INTRODUCTION}

Oxidative stress was caused by imbalance between the endogenous antioxidants and species reactive of oxygen (ROS) and nitrogen (RNS). ${ }^{1}$ Free radicals could be formed during the interaction of ROS/RNS with various biological components such as lipids and proteins. ${ }^{2-4}$ The imbalance between ROS/RNS and antioxidants is believed to lead to degenerative diseases such as diabetes, cancer and atherosclerosis. $^{5-7}$ Therefore, human body needs exogenous antioxidants to neutralize free radicals.

Antioxidants are groups of compounds having the capability to delay or prevent the oxidation reactions of biological components (lipids, proteins, nucleic acids) by retarding initiation and/or propagation

Correspondence to: A. Rohman

Email: abdul_kimfar@ugm.ac.id

Dhaka Univ. J. Pharm. Sci. 18(2): 145-152, 2019 (December) DOI: https://doi.org/10.3329/dujps.v18i2.43256 reactions of free radical. ${ }^{8}$ Based on its sources, antioxidants can be classified as natural antioxidants (coming from plants) and synthetic antioxidant coming from chemical synthesis. Some publications reported the negative effects of synthetic antioxidants. As a consequence, the need for natural antioxidants has increased currently because of the consumer concerns on safety issues. ${ }^{10}$ The exploration of antioxidants from underutilized part of fruit such as rambutan peel ${ }^{11}$ and mango peel ${ }^{12}$ was highlighted in order to reduce plant wastes.

Antioxidants isolated from plants are mainly coming from phenolics and flavonoids contents, therefore, evaluation of antioxidant activities is frequently correlated with the total contents of phenolics and flavonoids. ${ }^{13,14}$ Among antioxidant assay, radical scavenging methods is the most commonly used for antioxidant screening of plant 
extracts. ${ }^{15}$ In this study, the antiradical activities using DPPH and ABTS and its correlation with phenolics and flavonoid contents of extract and fractions of rambutan seed have been evaluated.

\section{MATERIALS AND METHODS}

Materials. Rambutan fruit was obtained from several locations in South Konawe, the province of Southeast Sulawesi, Indonesia. The fruit authenticity was performed in Department of Pharmaceutical Biology, Faculty of Pharmacy, Gadjah Mada University (UGM), Yogyakarta. The radicals of 2,2diphenyl-1-picrylhydrazyl (DPPH) and 2,2'azinobis(3-ethylbenzo thiazoline-6-sulphonic acid) diammonium salt (ABTS) were obtained from Sigma (Aldrich, USA). Trolox or 6-hydroxy-2,5,7,8tetramethylchroman-2-carboxylic acid, FolinCiocalteu reagent, gallic acid, and potassium persulphate were bought from E. Merck (Darmstadt, Germany). The other solvents and reagents used were of analytical grade.

Preparation of extract and fractions of rambutan seed. Preparation of extract and fractions of rambutan seed was carried according to Rohman et al. ${ }^{15}$ The rambutan seed was cut into small pieces using commercial cutter, and subjected to drying using conventional oven at $65^{\circ} \mathrm{C}$ for 2 days until dry and then powdered. The powder of rambutan seed was subjected to maceration with methanol (1: 10) for four days. The macerate was then filtered, and residue was then re-macerated for 2 days. The filtrates from two times of maceration were evaporated using vacuum rotary evaporator to obtain methanol extract. Furthermore, the methanolic extract was added to warm distilled water and then fractionated using petroleum ether (PE), dichloromethane (DCM) and ethyl acetate (EA) to get the corresponding fractions. The initial methanolic extract and the fractions (PE, DCM, EA and water) were used for antiradical assay as well as for determination of phenolics and flavonoid contents.

Evaluation of antiradical assays. Antiradical activities of extract and fractions of rambutan seed was evaluated using two radicals, namely 2.2diphenyl-1-picrylhydrazyl(DPPH) and 2,2'-azinobis(3-ethylbenzothiazoline-6-sulfonic acid) $\left(\mathrm{ABTS}^{\circ+}\right.$ ). For DPPH assay, $1.0 \mathrm{ml}$ DPPH $0.4 \mathrm{mM}$ in methanol was mixed with $50 \mu \mathrm{l}$ of extract or fractions at different concentrations and $3.950 \mathrm{ml}$ methanol (total volume of $5 \mathrm{ml}$ ). A control solution was prepared by adding $1 \mathrm{ml}$ of DPPH $(0.4 \mathrm{mM})$ with $4 \mathrm{ml}$ methanol. After 20 minute of operating time, the absorbance values were read at $517 \mathrm{~nm}$ using calibrated UV-Vis spectrophotometer against blank methanol.

$$
\% \text { Radical scavenging }=\frac{(\text { Abs control }- \text { Abs sample })}{\text { Abs control }} \times 100
$$

The DPPH radical activity was expressed with $\mathrm{IC}_{50}$, defined as the concentration of the samples needed to cause $50 \%$ scavenging of DPPH radical, calculated by an equation generated from linear regression. ${ }^{16}$ Vitamin $\mathrm{C}$ (ascorbic acid) and vitamin $\mathrm{E}$ (tocopherol) were used as positive controls. For ABTS assay, ABTS $(7 \mathrm{mM})$ and potassium persulphate $(2.45 \mathrm{mM})$ were mixed in ratio $1: 1$ and allowed to stand in the dark for 12-16 hrs to produce stock solution of ABTS radical cation $\left(\mathrm{ABTS}^{+}\right)$. This solution was further diluted with methanol to attain absorbance of $0.600-0.800$ at $734 \mathrm{~nm}$. The $\mathrm{ABTS}^{+}$working solution $(3 \mathrm{ml})$ and $30 \mu \mathrm{l}$ of blank, standard or sample were mixed and the absorbance was measured at $734 \mathrm{~nm}$ after 6 min using a spectrophotometer. The blank was run with methanol. A standard curve was prepared using Trolox solution $(0.3-1.5 \mathrm{mM}){ }^{17}$

Determination of phenolics and flavonoid contents. Both total phenolics and flavonoid contents were determined using calibrated visible spectrophotometer. Phenolics were read at $750 \mathrm{~nm}$ after reaction of samples with Folin-Ciocalteau reagent. ${ }^{18}$ Total phenolic contents were calculated as gram gallic acid equivalent/100 gram of dry samples. For flavonoid contents, the samples were reacted 
with aluminum chloride and measured at $512 \mathrm{~nm} .{ }^{19}$ Total flavonoid contents of extract and fractions were expressed as gram of rutin equivalent/100 gram dry material.

Data analysis. All data of antiradicals and its related data were analyzed in triplicate and expressed as mean \pm standard deviation using Excel (Microsoft Inc., USA).

\section{RESULTS AND DISCUSSION}

Among antioxidant assays, the use of reactive radicals scavenged by active compounds is the most popular methods reported by some authors. Two radicals are typically used, namely 2,2'-diphenyl-1picrilhydrazil (DPPH) radical and 2,2'-azinobis(3ethylbenzo thiazoline-6-sulphonic acid) diammonium salt cation radical $\left(\mathrm{ABTS}^{+}\right)$. Any compounds capable of scavenging both radicals could be taken into account as antioxidant. The main requirement of samples to be active as radical scavengers is the capability to give hydrogen radicals into DPPH or ABTS. Typical compounds that meet this requirement are phenolics and flavonoids. The reduction of colour intensity of both radicals due to addition of evaluated samples indicated that studied samples can act as radical scavengers. ${ }^{20}$ Figure 1 compiled $\mathrm{IC}_{50}$ values of extract and fractions of rambutan seed using DPPH assay. The lower the $\mathrm{IC}_{50}$, the higher the antiradical activities. EA fraction has the lowest $\mathrm{IC}_{50}$ indicating that it was the most active antiradicals in DPPH assay. However, the antiradical activities of studied extracts and fractions were lower than those of vitamin $\mathrm{C}$ with $\mathrm{IC}_{50}$ of 3.70 $\pm 0.05 \mu \mathrm{g} / \mathrm{ml}$ and vitamin $\mathrm{E}$ with $\mathrm{IC}_{50}$ of $2.65 \pm 0.04$ $\mu \mathrm{g} / \mathrm{ml}$.

The antiradical activity of samples using ABTS radical was expressed as Trolox equivalent as in figure 2. Among the evaluated samples, ethyl acetate fraction exhibited the highest Trolox equivalent with value of $729 \mu \mathrm{M}$ compared with other extract and fractions. This indicated that EA fraction had highest antiradical activities compared with others. In order to isolate the active compound responsible for antiradical activities, EA fraction was subjected to further fractionation.

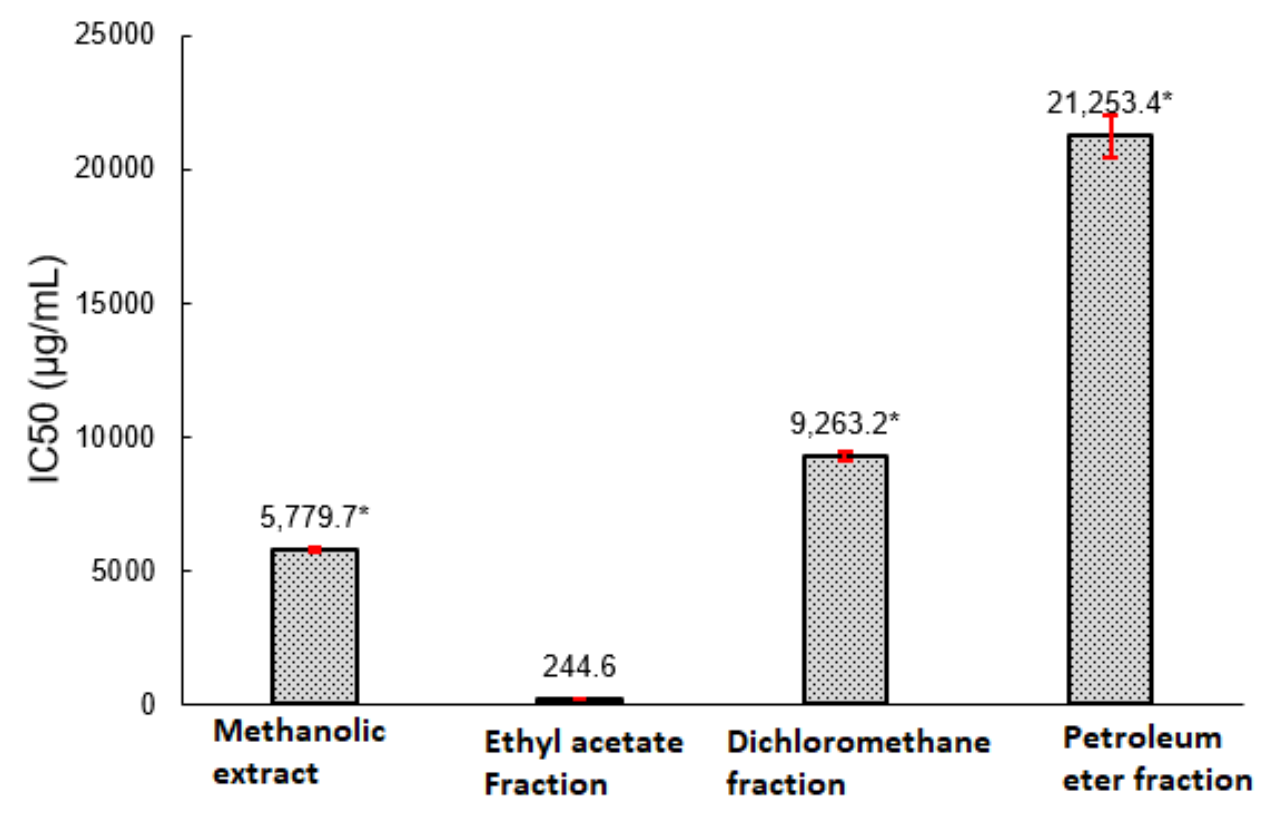

Figure 1. The $\mathrm{IC}_{50}$ values of methanolic extract and its fractions of Rambutan peel using DPPH radical assay. 


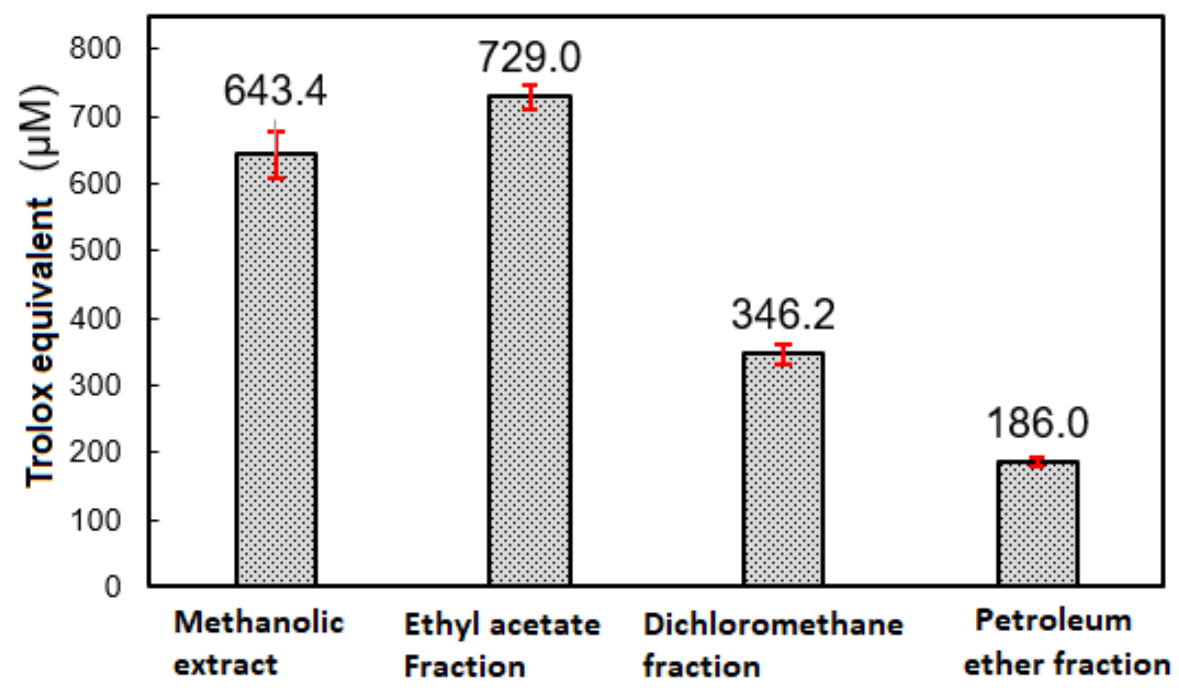

Figure 2. The antiradical activities of methanolic extract and its fractions using ABTS radical, as expressed with Trolox equivalent.

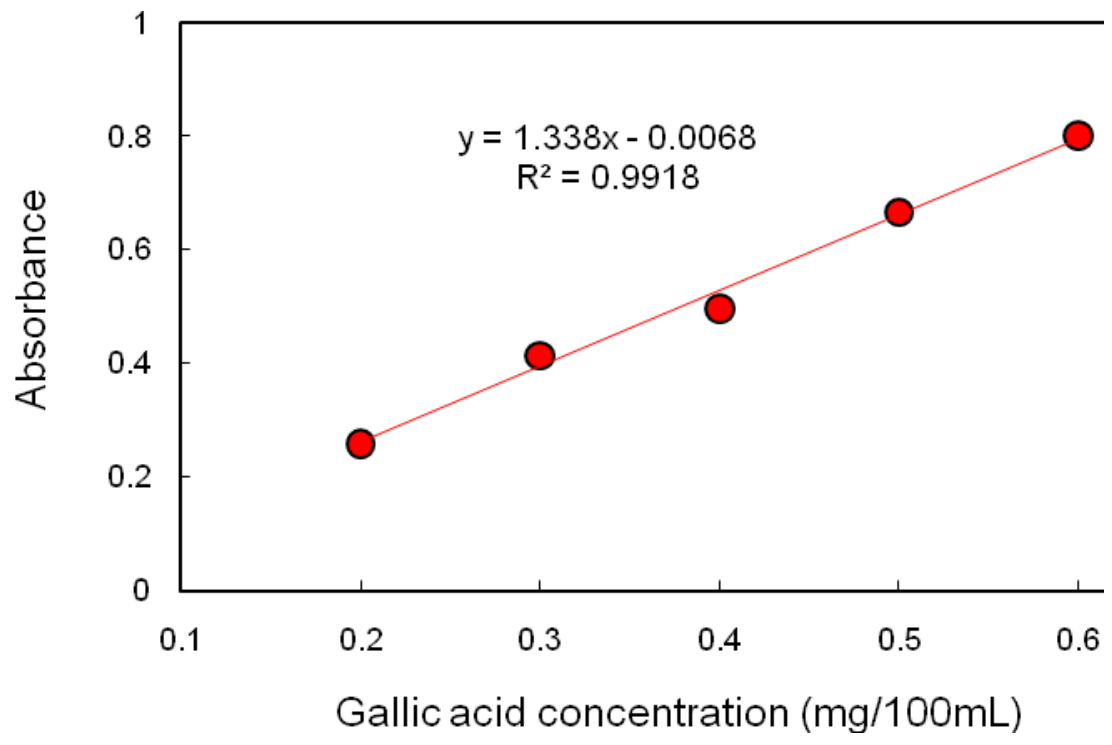

Figure 3. The correlation between gallic acid concentration (x-axis) and its absorbance after reaction with Folin Ciocalteau reagent.

Phenolics and flavonoids are believed to be responsible for antiradical activities due to its capability to donate hydrogen radicals into ABTS and DPP radicals. As a consequence, antioxidant activities from natural sources are correlated with the total phenolics and flavonoids contents. Figure 3 revealed the calibration curve describing the relationship between gallic acid concentration, used as phenolics standard (x-axis) and its absorbances due to reaction between gallic acid and Folin
Ciocalteau reagent (y-axis). The coefficient of determination was 0.9918 indicating that the linear regression equation was acceptable for predicting phenolic contents. The phenolic contents were expressed as gallic acid equivalent (GAE) in $100 \mathrm{~g}$ samples of extract and fractions.

The phenolic contents of methanolic extract and its fractions are shown in figure 4. EA fraction exhibited the highest phenolics content $(0.072 \%$ GAE), compared to others. This result was in 
agrement with antiradical activities, in which EA revealed the highest antiradical activity. This supported the correlation between phenolics contents and antiradical activities either with DPPH or ABTS radicals.

Figure 5 revealed the correlation between phenolics contents and antiradical activities using DPPH (A) and ABTS (B). The linear regression equation obtained for the correlation between total phenolic content (TPC) (x-axis) with $\mathrm{IC}_{50}$ values (yaxis) has $\mathrm{R}^{2}$ of 0.69576 , which showed that $69.58 \%$ of
DPPH radical scavenging activities were from contribution of phenolic compounds and the other contribution come from other compounds, indicating moderate correlation between $\mathrm{IC}_{50}$ values and TPC. ${ }^{20}$ The higher $\mathrm{R}^{2}$ value was obtained for the relationship between TPC and antiradical activities using ABTS radicals, i.e. 0.81828. This indicated that phenolic compounds present in rambutan peel were more active toward ABTS radical than DPPH radicals, however, the individual phenolics responsible for these activities have not been reported yet.

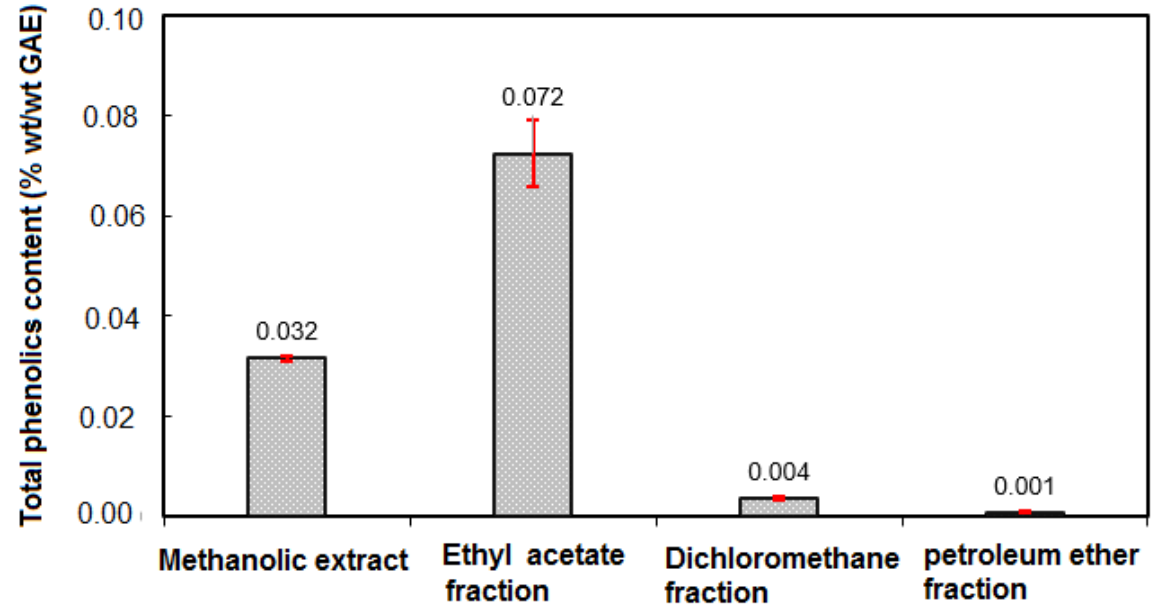

Figure 4. The phenolics content of methanolic extract and its fractions of Rambutan seed, expressed as \% wt/wt gallic acid equivalent.
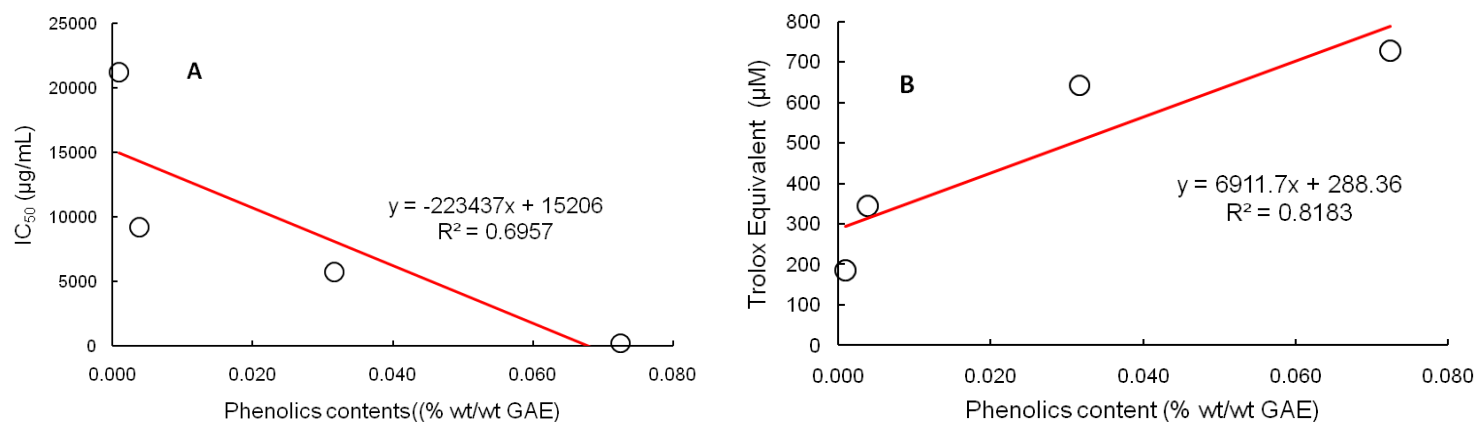

Figure 5. The correlation between phenolic content and antiradical activities of methanolic extract of rambutan seed and its fractions using DPPH (A) and ABTS (B)

Figure 6A showed the relationship between rutin concentration, used as flavonoid standard (x-axis) and its absorbances due to reaction with $\mathrm{AlCl}_{3}$ followed with $\mathrm{NaOH}$. The $\mathrm{R}^{2}$ was found to be 0.9947 indicating the linear regression equation was acceptable for predicting flavonoid contents. EA fraction also had the highest flavonoid contents, i.e. $4.98 \% \mathrm{wt} / \mathrm{wt}$ rutin equivalent (RE), among extract and fractions evaluated, therefore it is interesting to correlate between flavonoid contents and radical activities. 
Figure 7 revealed the correlation between the total flavonoid content (TFC) (x-axis) and antiradical activities, using DPPH radicals (A) and ABTS radicals (B). Using DPPH radicals, $\mathrm{R}^{2}$ found was 0.47326 , indicating that $47.33 \%$ of DPPH radical scavenging activity came from the contribution of flavonoid content. Using ABTS radicals, the correlation between TFC and Trolox equivalent had $\mathrm{R}^{2}$ of 0.46736 , which showed that $46.74 \%$ of ABTS radical scavenging was from the contribution of flavonoid compounds.

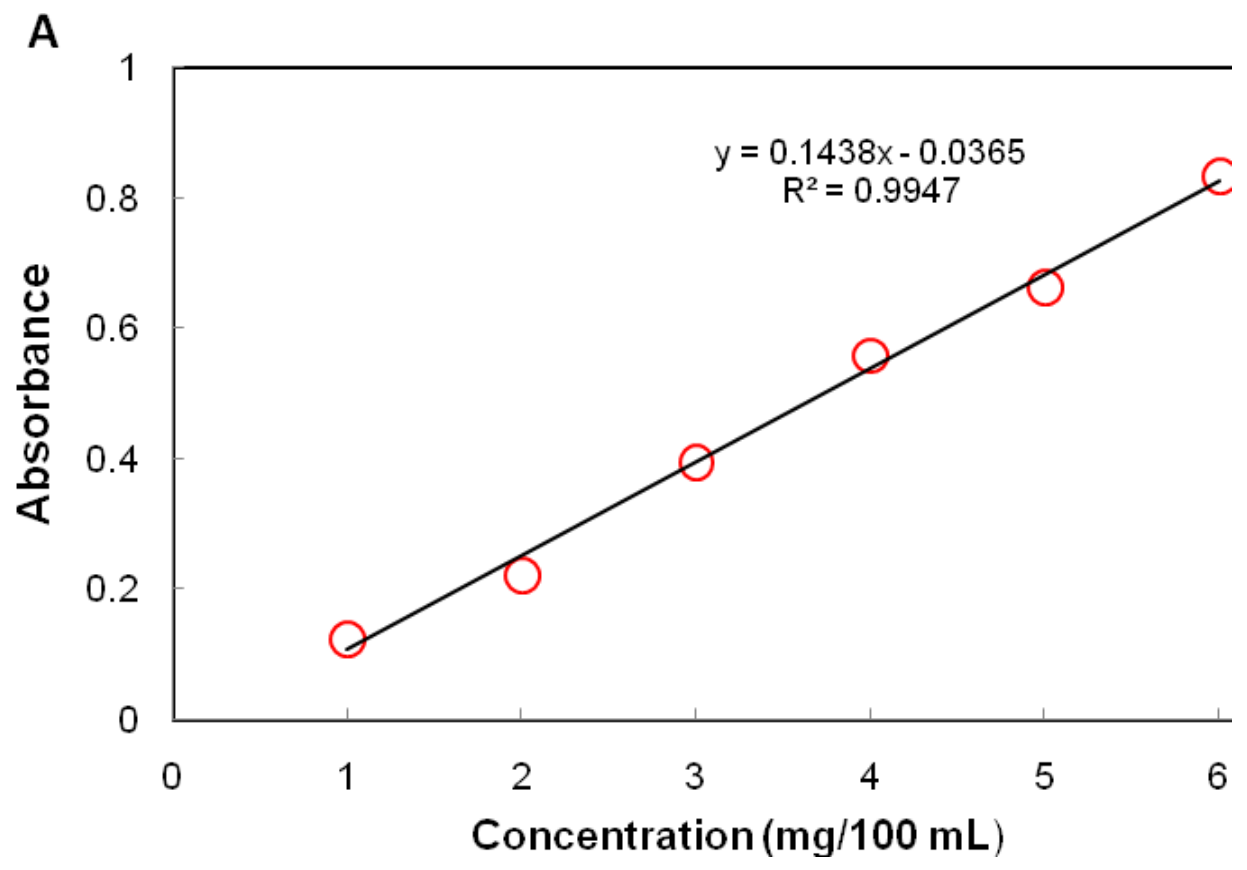

B

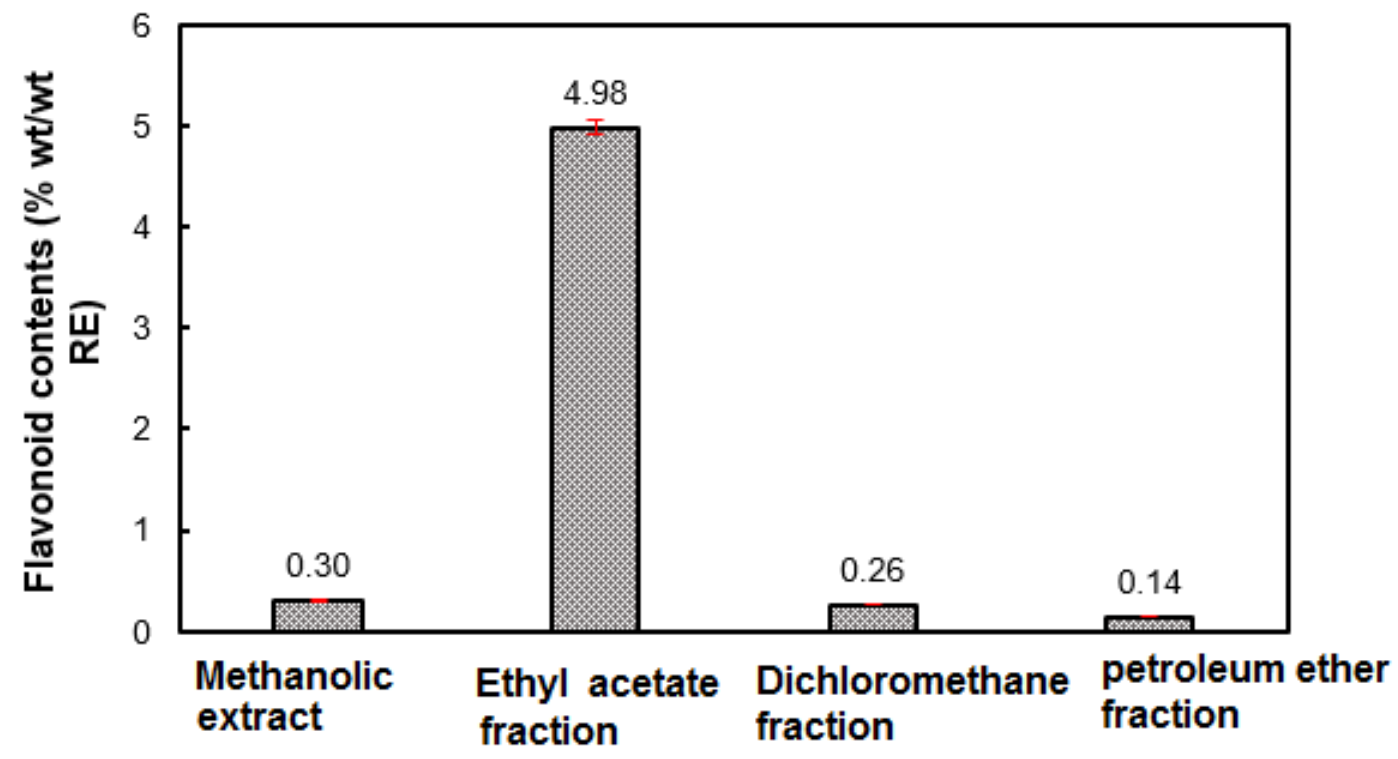

Figure 6. The correlation between rutin concentration (x-axis) and its absorbance (A) and the flavonoid contents of methanolic extract of Rambutan seed and its fractions, expressed as \% wt/wt rutin equivalent. 

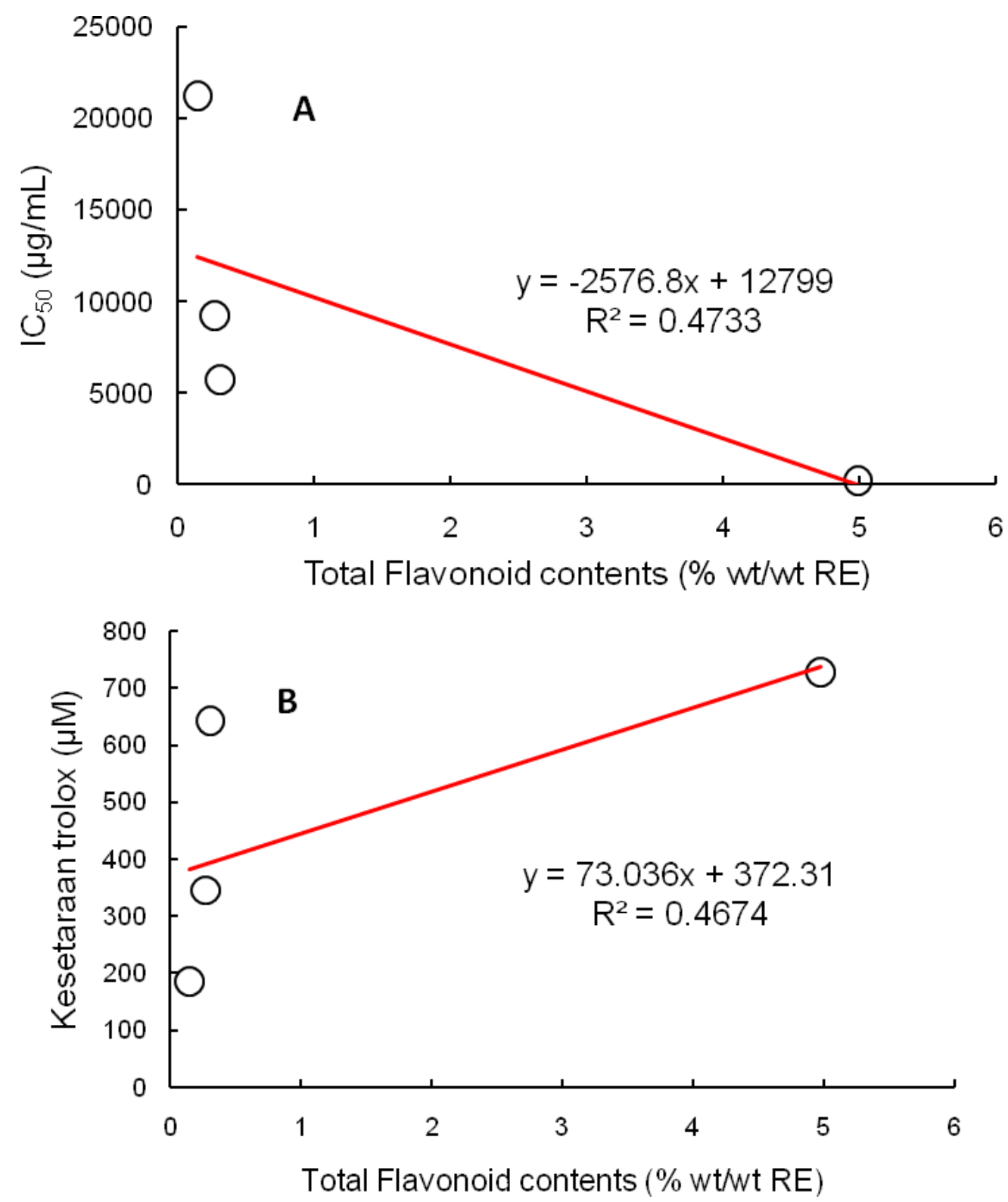

Figure 7. The correlation between flavonoid content and antiradical activities of methanolic extract of rambutan seed and its fractions using DPPH (A) and ABTS (B).

\section{CONCLUSION}

Among methanolic extract and its fraction of rambutan seed, the ethyl acetate soluble fraction has the most antiradical activities using both DPPH and ABTS radicals. These antiradical activities were correlated with total phenolic and flavonoid contents. Oleic acid was among compounds identified in ethyl acetate fraction.

\section{ACKNOWLEDGEMENT}

The authors thank to the Ministry of Higher Education, Republic of Indonesia for financial assistance during research activities via Penelitian Dasar Unggulan Perguruan Tinggi 2017-2018. 


\section{CONFLICT OF INTEREST}

We declared that there is no conflict of interest during research activity and publication

\section{AUTHORS CONTRIBUTION}

MJB compiled data and analyzed data. Rum, SR, and $\mathrm{AR}$ designed research, prepared manuscript and finalized the manuscript.

\section{REFERENCES}

1. Persson, T., Popescu, B.O. and Cedazo-Minguez, A. 2014. Oxidative stress in Alzheimer's disease: why did antioxidant therapy fail. Oxid. Med. Cell Longev. Article ID 427318, 11 pages, http://dx.doi.org/10.1155/2014/427318.

2. Fidrianny, I., Sukowati, A. and Sukrasno. 2014. In vitro antioxidant activities of various leaves extracts from five varieties of rambutan (Nephelium lappaceum) and its correlation with total flavonoid, phenolic, carotenoid content. Asian J. Pharm. Clin. Res. 8, 139-143.

3. Fidrianny, I., Yuniar, I.F. and Insanu, M. 2015. Antioxidant activities of various seed extracts from four varieties of rambutan (Nephelium lappaceum) using 2,2-diphenyl-1picrylhydrazyl and 2,2'-azinobis (3-ethyl-benzothiazoline-6sulfonic acid) assays. Int. J. App. Pharm. 8, 215-219.

4. Pisoschi, A.M. and Pop, A. 2015. The role of antioxidants in the chemistry of oxidative stress: A review. Eur. J. Med. Chem. 97, 55-74. Doi: https://doi.org/10.1016/ j.ejmech. 2015.04.040.

5. Lefer, D.J. and Granger, D.N. 2000. Oxidative stress and cardiac disease. Am. J. Med. 109, 315-323.

6. Bhatia, S., Shukla, R., Madhu, S.V., Gambhir, J.K. and Prabhu, K.M. 2003. Antioxidant status, lipid peroxidation and $\mathrm{NO}$ end products in patients of type 2 diabetes mellitus with nephropathy. Clin. Biochem. 36, 557-562.

7. Peuchant, E., Brun, J., Rigalleau, V., Dubourg, L., Thomas, M. and Daniel, J. 2004. Oxidative and antioxidative status in pregnant women with either gestational or type 1 diabetes. Clin. Biochem. 37, 293-298.

8. Di Carlo, G., Mascolo, N., Izzo, A.A. and Capasso, F. 1999. Flavonoids old and new aspects of a class of natural therapeutic drugs. Life Sci. 65, 337-533.
9. Alnajar, Z.A.A., Abdulla, M.A., Ali, H.M., Alshawshand, M.A. and Hadi, A.H.A. 2012. Acute toxicity evaluation, antibacterial, antioxidant and immunomodulatory effects of Melastoma malabathricum. Molecules. 17, 3547-3559.

10. Valentao, P., Fernandes, E., Carvalho, F., Andrade, P.B., Seabra, R.M. and Bastos, M. 2002. Antioxidative properties of cardoon (Cynara cardunculus L.) infusion against superoxide radical, hydroxyl radical and hypochlorous acid. J. Agric. Food Chem. 50, 4989-4993.

11. Permatasari, L. and Rohman, A. 2016. 2,2'-diphenil-1picrylhydrazil (DPPH) radical scavenging activity of extracts and fractions of Rambutan (Nephelium lappaceum L.) Peel. Res. J. Phytochem. 10, 75-80.

12. Sogi, D.S., Siddiq, M., Greiby, I. and Dolan, K.D.2013. Total phenolics, antioxidant activity, and functional properties of 'Tommy Atkins' mango peel and kernel as affected by drying methods. Food Chem. 141, 2649-2655.

13. Rohman, A., Riyanto, S., Yuniarti, N., Saputra, W.R., Utami, R. and Mulatsih, W. 2010. Antioxidant activity, total phenolic, and total flavaonoid of extracts and fractions of red fruit (Pandanus conoideus Lam). Int. Food Res. J. 17, $97-$ 106.

14. Javanmardi, J., Stushnoff, C., Locke, E. andVivanco, J.M. 2003. Antioxidant activity and total phenolic content of Iranian ocimum accessions. Food Chem. 83, 547-550.

15. Rohman, A., Riyanto, S. and Utari, D. 2006. Antioxidant activities, total phenolic and flavonoid contents of ethyl acetate extract of Mengkudu (Morinda citrifolia, L) fruit and its fractions. Indonesian J. Pharm. 17, 136-142.

16. Re, R., Pellegrini, N., Proteggente, A., Pannala, A., Yang, M. and Rice-Evans, C. 1999. Antioxidant activity applying an improved ABTS radical cation decolorization assay. Free Rad. Biol. Med. 26, 1231-1238.

17. Chun, O.K., Kim, D.O. and Lee, C.Y. 2003. Superoxide radical scavenging activity of the major polyphenols in fresh plums. J. Agric. Food Chem. 51, 8067-8072.

18. Zou, Y., Lu, Y. and Wei D. 2004. Antioxidant activity of flavonoid-rich extract of Hypericumperforatum $\mathrm{L}$ in vitro. $J$. Agric. Food Chem. 52, 5032-5039.

19. Budikafa, M.J.2017. Identification and Antioxidant activity of extract and fractions of rambutan (Nephelium lappaceum L.) seed in vitro. Thesis, Faculty of Pharmacy, Universitas Gadjah Mada, Yogyakarta, Indonesia.

20. Mistriyani, Riyanto, S. and Rohman, A. 2018. Antioxidant activities of Rambutan (Nephelium lappaceum L) peel in vitro. Food Res. 2, 119 -123. 